\title{
UNIFICANDO A ALOCAÇÃO DE CAPITAL EM BANCOS E SEGURADORAS NO BRASIL
}

RESUMO

Um dos motivos para a recente evolução da gestão de riscos em bancos internacionais é a proposta contida no Novo Acordo de Capital da Basiléia. Essa proposta busca uma maior especialização na alocação de capital em função dos riscos presentes nas atividades dos bancos, tendência que já vem sendo refletida no ambiente regulamentar local pelo Banco Central do Brasil. A gestão de riscos e a alocação de capital em seguradoras no mercado internacional encontram-se em um processo de convergência acelerada para os princípios requeridos dos bancos. $O$ mesmo não pode ser dito no que se refere ao ambiente regulamentar para as seguradoras no Brasil, que ainda se encontra em um estágio de desenvolvimento inferior quando comparado a seu equivalente local para bancos. Neste ensaio, apresentamos as diferenças existentes entre os ambientes de requerimento regulamentar de capital para bancos e seguradoras no Brasil. Nosso objetivo é propor a unificação desses ambientes no mercado brasileiro, apresentando uma sugestão de como tal unificação deve ser conduzida.

\section{Antonio Marcos Duarte Júnior \\ Faculdades Ibmec}

\section{Rogério José Furigo Lélis}

Unibanco S. A.

\begin{abstract}
The New Basel Capital Accord is one of the main reasons behind the recent evolution of risk management in international banks. This proposal requires that capital be allocated to face the risks present in banks. This international trend is already being reflected in the Brazilian regulatory environment for banks. The regulatory environment for risk management and capital allocation for insurance companies is converging quickly to that of banks in international markets. The same is not true for the Brazilian regulatory environment for insurance companies, which is still far behind that of banks. In this article we present the main differences between the regulatory environment for capital allocation faced by banks and insurance companies in Brazil. Our main objective is to propose a unified regulatory framework to require capital in both banks and insurance companies in Brazil, showing how this convergence should be conducted.
\end{abstract}

PALAVRAS-CHAVE Alocação de capital, capital econômico, capital regulamentar, gestão de riscos, Novo Acordo de Capital da Basiléia. KEY WORDS Capital allocation, economic capital, regulatory capital, risk management, New Basel Capital Accord. 


\section{INTRODUÇÃo}

Durante o período que se estende do início dos anos 1940 até meados da década de 1970, os bancos internacionalmente ativos puderam operar em um ambiente de grande estabilidade e de pouca competição. $\mathrm{O}$ colapso de Bretton Woods na década de 1970 produziu, dentre outros resultados, um ambiente caracterizado, em grande medida, pela presença de taxas de juros e câmbio mais voláteis. Nesse cenário, alguns bancos adotaram estratégias de negócio que se mostraram erradas ao longo do tempo, como, por exemplo, a opção por atuar na presença de uma excessiva alavancagem financeira sem uma análise de riscos adequada (Matten, 1998). Os prejuízos acumulados e a erosão do capital desses bancos alarmaram os supervisores bancários, levando à formação do Comitê da Basiléia para Supervisão Bancária, composto inicialmente por representantes dos bancos centrais dos países do G10.

O Comitê da Basiléia propôs, em 1988, o Acordo de Capital da Basiléia - ACB (Bank for International Settlements, 1988). O principal objetivo do ACB foi fortalecer o sistema bancário por meio da recomendação de constituição de um capital mínimo por parte dos bancos, de forma a minimizar os riscos de insolvência e, por conseguinte, os riscos sistêmicos. Apesar de suas recomendações não possuírem força legal, os países do G10 regulamentaram as medidas em 1992. No Brasil, o reflexo direto do ACB deu-se em 1994, com a publicação da Resolução 2.099 (Banco Central do Brasil, 1994).

Um avanço substancial em relação ao acordo de 1988 é o Novo Acordo de Capital da Basiléia - NACB (Bank for International Settlements, 2001a). A mensagem mais importante colocada pelo NACB é que as instituições financeiras devem buscar, de forma espontânea, avanços na identificação, quantificação e gestão de riscos.

O NACB está estruturado sobre três "pilares". O primeiro deles descreve metodologias para o cálculo de requisitos mínimos de capital para fazer frente a riscos. Essa nova proposta visa estabelecer uma maior diferenciação dos riscos presentes nas instituições financeiras. Por exemplo, riscos operacionais passaram a requerer capital regulamentar. O segundo pilar requer uma maior proximidade entre a Supervisão Bancária e a Diretoria Executiva dos bancos internacionalmente ativos. Essa nova proposta visa a tornar a Supervisão Bancária mais atuante, aumentando sua ingerência no banco quando se notar um aumento significativo de riscos. Por fim, o terceiro pilar refere-se à transparência que deve ser dada pelas instituições financeiras sobre suas exposições a riscos. Essa nova proposta visa disciplinar os bancos internacionalmente ativos, permitindo uma melhor visualização de seus riscos, principalmente pela Supervisão Bancária.

No mercado segurador, uma série de eventos adversos causou, entre 1980 e 1994, um crescimento do número de seguradoras e resseguradoras insolventes no cenário internacional. Forte instabilidade nos resultados, comportamento adverso dos sinistros em função de grandes desastres naturais, significativa tendência ao crescimento do nível das provisões para perdas, flutuações nas taxas de juros e decisões de investimento em ativos de elevado risco foram alguns dos fatores que contribuíram para o crescimento do número de insolvências (European Parliament, 2002). No período citado, aproximadamente 650 seguradoras tornaram-se insolventes. Responsáveis por aproximadamente $50 \%$ dos prêmios emitidos no mercado internacional, os Estados Unidos contaram com cerca de 70\% dessas ocorrências (Cross e Hershbarger, 1997). Como conseqüência desses eventos, houve uma série de críticas ao sistema de regulamentação de seguradoras (Hooker et al., 1996).

Em resposta às críticas, a National Association of Insurance Comissioners - NAIC - estabeleceu um grupo de trabalho para a elaboração de um novo modelo de requerimento de capital. Esse novo modelo baseava-se no princípio de que o capital deve ser alocado para fazer frente aos riscos assumidos pelas companhias seguradoras. Os documentos consultivos foram distribuídos em 1991. Os membros da NAIC adotaram o modelo de requerimento de capital em 1992, no caso das companhias do ramo vida, e em 1993, no caso das companhias dos ramos elementares (seguradoras de bens e responsabilidades, como automóveis, residências etc.), tal como assinalado em Atchinson (1996).

No cenário europeu, as primeiras regras de constituição de margem de solvência datam de 1973, para companhias de ramos elementares, e de 1979, para as do ramo vida. A sistemática desse cálculo, que utiliza o comportamento dos prêmios, sinistros e do montante de reservas técnicas constituídas, refletiuse no Brasil por meio da Resolução CNSP 08 (Conselho Nacional de Seguros Privados, 1989), que passou a exigir a constituição de uma margem de solvência. 
Ainda na Europa, em julho de 2001, foram aprovadas, sob o projeto denominado Solvência I, as propostas de alterações dos requerimentos de margem de solvência da década de 1970 (European Parliament, 2000a, 2000b). O projeto teve como objetivo principal o fortalecimento das regras de constituição de um patamar mínimo do patrimônio líquido das companhias seguradoras por meio da revisão e alteração de fatores aplicados sobre prêmios, sinistros e reservas técnicas constituídas. No Brasil, essas alterações puderam ser observadas na Resolução CNSP 55 (Conselho Nacional de Seguros Privados, 2001).

A Comissão das Comunidades Européias já discute hoje o projeto Solvência II, que propõe a utilização de abordagens mais sofisticadas para o cálculo da margem de solvência. O projeto sugere examinar aqueles elementos ainda não considerados pelo cálculo atual, como arranjos de resseguros, nível de provisões técnicas, política de investimentos - considerando riscos de mercado e crédito -, gerenciamento conjunto de ativos e passivos, e riscos operacionais. Trata-se de um conjunto de regras que irá utilizar modelos mais sofisticados de quantificação de riscos, e cujo principal objetivo caminha em paralelo ao do Novo Acordo de Capital da Basiléia: determinar de forma mais precisa a constituição de um capital mínimo em função dos riscos assumidos (European Parliament, 2001a, 2001b). Esse objetivo principal é convergente com os princípios que devem ser seguidos por companhias seguradoras para a constituição de um capital mínimo, como colocado pela International Association of Insurance Supervisors (2002).

Há, no histórico apresentado até aqui, para bancos e seguradoras, uma clara tendência de convergência na gestão de riscos e alocação de capital nos mercados internacionais. E o elemento comum entre os dois tipos de negócio é a identificação e quantificação dos riscos assumidos. Assim é plausível esperar que no médio e longo prazo as regras de regulamentação de constituição de capital mínimo para bancos e seguradoras unifiquem-se, conforme já vem sendo manifestado em outros mercados como, por exemplo, no caso britânico (Financial Services Authority, 2001).

Em vista da tendência apontada acima, este texto buscará demonstrar que a unificação do ambiente regulamentar para gestão de riscos e alocação de capital para bancos e seguradoras no Brasil é uma medida fundamental para o controle das situações geradoras ou destruidoras de valor. Para defender esta tese, o texto apresenta (1) alguns conceitos centrais em gestão de riscos corporativos; e (2) os fundamentos da alocação de capital em bancos e seguradoras, diferenciando capital regulamentar e capital econômico. Uma vez criada esta base conceitual, são então apresentadas (3) a proposta de unificação do ambiente regulamentar para bancos e seguradoras; e (4) as principais dificuldades da viabilização desta proposta. O texto é, por fim, encerrado com algumas conclusões e apontamentos de perspectivas futuras sobre o tema.

\section{COMO FAZER GESTÃO DE RISCOS CORPORATIVOS}

A existência de uma área para a gestão de riscos com uma visão corporativa é um passo necessário para a alocação de capital em um banco ou em uma seguradora. As áreas para gestão de riscos devem ter como seus objetivos a identificação, o mapeamento, a medição e a consolidação das exposições a riscos, cobrindo em conglomerados financeiros, por exemplo, as operações de finanças corporativas, tesouraria, redes de agências bancárias, operação com cartões de crédito, administração de recursos de terceiros - incluindo private banking e previdência privada -, operações de seguros etc.

A importância de uma gestão de riscos efetiva, com visão corporativa, para uma alocação de capital em bancos está baseada em quatro elementos fundamentais (Federal Reserve System, 1999). Vejamos cada um deles.

O primeiro diz respeito à identificação, ao mapeamento, à medição e consolidação das exposições a riscos, ou seja, os sistemas internos de gestão de riscos de bancos e seguradoras devem identificar, mapear, medir e consolidar as exposições a riscos de forma geral e consistente, diferenciando da forma mais precisa possível os tipos de riscos e níveis de exposição.

O segundo elemento refere-se ao relacionamento entre capital requerido e níveis de exposições a riscos presentes. O princípio básico a nortear o processo de alocação de capital deve se originar das exposições de riscos detectadas, exigindo maiores níveis de capital para aquelas atividades/unidades que apresentem maiores exposições a riscos. O primeiro pilar do NACB está aqui refletido.

O terceiro elemento postula que os objetivos da alocação de capital devem estar ligados ao nível de exposição a riscos, ou seja, no momento do processo orçamentário, os níveis de exposição a riscos devem ser 
previstos, exigindo-se que a alocação de capital seja preventivamente considerada em relação à projeção de resultados - incluindo aumento de ativos, de provisões etc.

Por último, o quarto elemento relaciona-se à verificação da adequação de capital aos níveis de riscos incorridos. Isso quer dizer que o capital alocado para diferentes atividades/unidades deve prover segurança de forma a não se tornar insuficiente, buscando, assim, garantir a solvência da instituição, mesmo em situações adversas de mercado. O segundo pilar do NACB está aqui refletido.

O trabalho de alocação de capital só pode ser iniciado após a fase de consolidação de riscos. Sem uma visão consolidada de riscos no banco ou na seguradora, cobrindo todas as dimensões de riscos presentes, não há possibilidade de sucesso prático para a implementação de uma metodologia de alocação de capital (Froot e Stein, 1998; Shepheard-Walwyn e Litterman, 1998).

Como um passo básico para a identificação de riscos de forma padronizada em bancos e em seguradoras é necessário o estabelecimento de uma linguagem comum entre seus profissionais. Isso pode ser obtido por meio da elaboração e divulgação de uma lista de riscos, como ilustrado no Quadro 1. Essa lista deve ser acompanhada de vários exemplos que estabeleçam uma clara ligação entre suas definições e a rotina diária dos profissionais de bancos e seguradoras (Duarte et al., 1999). De forma similar, uma lista de controles para bancos e seguradoras também deve ser criada (Duarte et al., 2001), onde se poderiam incluir controles, por exemplo, de alçadas e limites; de autorizações; de conciliação; de acesso físico e lógico; de manutenção de registros; de normatização interna; de segregação de funções; de responsabilidades; de pla- nos de contingência; de informações; dentre outros tipos de controle.

A identificação dos riscos pode ser feita por unidades - de negócios e serviços -, por produtos e serviços, ou por processos internos. Nossa sugestão, no entanto, é que se inicie com a visão de unidades de negócios e serviços, seguida da visão por produtos e serviços e, por fim, da visão por processos internos.

São cinco os passos necessários para a análise de unidades. O primeiro passo envolve uma divisão do conglomerado em suas principais unidades (de negócios ou de serviços). Por exemplo, essa divisão pode seguir o organograma da instituição. Em segundo lugar, são necessárias a identificação e a descrição das principais atividades da rotina diária de cada uma dessas unidades. O terceiro passo diz respeito à identificação dos riscos envolvidos em cada uma das atividades da unidade. Essa identificação deve seguir, necessariamente, uma padronização - tal como ilustrado pelo Quadro 1 -, do contrário, não haverá uniformidade usada na linguagem do conglomerado. Em quarto lugar é preciso fazer um detalhamento rigoroso de todos os controles internos usados para mitigar os respectivos riscos. Novamente se faz necessária aqui uma padronização. Por fim, o quinto passo consiste na realização de um julgamento sobre a efetividade do controle praticado. Esse julgamento deve ser feito em conjunto pela área de Gestão de Riscos Corporativos, Auditoria Interna e pela própria unidade. Se julgado insuficiente para mitigar o risco considerado, deve-se estabelecer um plano de ação para a melhoria do controle até um nível considerado aceitável pelas áreas de Gestão de Riscos Corporativos e Auditoria Interna.

A realização criteriosa desses cinco passos proporcionará ao banco ou à seguradora uma boa identificação dos riscos presentes na rotina de cada uma de suas

\section{Quadro 1 - Exemplo de uma lista de riscos para bancos.}

\begin{tabular}{|c|c|c|c|}
\hline RISCOS DE CRÉDITO & RISCOS DE MERCADO & RISCOS OPERACIONAIS & RISCOS LEGAIS \\
\hline Inadimplência & Taxas de juros & Fraudes, furtos e roubos & Tributário \\
\hline Degradação de crédito & Taxas de câmbio & Lavagem de dinheiro & Contratos \\
\hline Degradação de garantias & Ações & Liquidação financeira & Legislação \\
\hline Soberano & Commodities & Erros humanos & \\
\hline Concentração de carteiras & Liquidez & Equipamento & \\
\hline & Derivativos & Overload de sistemas & \\
\hline & Hedge & Produtos e serviços & \\
\hline & Catástrofe & \\
\hline
\end{tabular}


unidades principais. É importante reconhecer a complementaridade que há entre a análise de unidades, a de produtos e serviços, e a de processos. O resultado final será uma visão dos riscos presentes e dos controles internos utilizados para mitigar esses riscos para cada produto, serviço e processo no conglomerado.

Um processo sistemático de cálculo de alocação de capital realizado em uma área com visão de riscos corporativos, segundo o método aqui citado, não é tarefa fácil: envolverá custos financeiros significativos e enfrentará barreiras culturais para sua implementação. Deverá gerar, entretanto, uma análise mais precisa do grau de solvência de bancos e seguradoras frente aos riscos assumidos e, ao possibilitar a análise de índices de eficiência e de valores adicionados aos acionistas, um benefício expressivo para a tomada de decisões de investimento. Assumindo que todas as etapas descritas nesta seção tenham sido fielmente cumpridas, podemos passar à alocação de capital em bancos e seguradoras.

\section{FUNDAMENTOS DA ALOCAÇÃO DE CAPITAL}

O processo de alocação de capital deve, necessariamente, cobrir pelo menos duas abordagens: 1) o Capital Regulamentar, aquele dado pelo mínimo requerido pela autoridade regulamentar para preservar a integridade da instituição - e, por conseguinte, do capital de terceiros e dos acionistas -, buscando garantir sua solvência em condições adversas de mercado; e 2) o Capital Econômico, aquele dado pelo excesso de ativos sobre passivos, necessário para proteger a instituição do potencial colapso, garantindo aos acionistas retornos futuros, mesmo diante das incertezas enfrentadas pelo negócio.

Existem algumas diferenças entre Capital Regulamentar e Capital Econômico. Por exemplo, o Capital Econômico é mais difícil de ser calculado do que o Capital Regulamentar, mas é também uma melhor estimativa em termos para os riscos inerentes da instituição, além de ser mais útil quando se consideram as aplicações relacionadas ao valor adicionado ao acionista (Hallerbach, 2001; Stoughton e Zechner, 1999, 2000). O motivo básico para isso é que a forma de cálculo do Capital Regulamentar é usualmente, rígida, seguindo formato descrito em normativos emitidos pelos órgãos de regulamentação, conforme destaca Lofrano (2001). Por sua vez, as formas de cálculo do Capital Econômico são mais elaboradas, valendo- se, na grande maioria das vezes, de técnicas estatísticas e econométricas, tal como ilustrado por Lélis e Duarte (2002). Existem também as chamadas "abordagens subjetivas" para estimação do Capital Econômico, conforme descrito em Payant (1996), as quais não recomendamos por não apresentarem sólidos fundamentos técnicos.

O ideal é termos o Capital Econômico alocado em cada atividade, unidade, processo, produto ou serviço, haja vista sua maior precisão na medição dos riscos presentes. No entanto, dado que há o requerimento de Capital Regulamentar, o valor máximo entre este último e o Capital Econômico deve ser sempre adotado de forma a satisfazer os normativos em vigor. Como nosso foco neste trabalho está relacionado aos ambientes de regulamentação para bancos e seguradoras no Brasil, concentramo-nos daqui para diante somente na alocação de Capital Regulamentar.

\section{Alocação de Capital Regulamentar em bancos no Brasil}

A evolução da demanda por Capital Regulamentar para bancos no Brasil começa com o requerimento de capital iniciado no momento da implementação da versão local - Resolução 2.099 - do Acordo de Capital da Basiléia de 1988. A demanda fica restrita somente ao risco de crédito, excluídas as exposições a derivativos.

Além disso, sofistica-se o requerimento de Capital Regulamentar, que passa a incluir as operações de swaps - Resolução 2.399 - sem mencionar os demais derivativos de particular interesse para os bancos que operam no Brasil, como futuros, opções e operações a termo. Em 1994, o mercado brasileiro de derivativos ainda não havia atingido o nível de sofisticação dos dias de hoje, principalmente pelo desenvolvimento trazido ao longo dos últimos anos ao mercado local pela Bolsa de Mercadorias e Futuros. Por outro lado, ainda atualmente, a demanda de capital para exposições de crédito resultantes de posicionamentos em derivativos permanece restrita a operações de swaps, o que é insuficiente e terá de ser alterado no futuro, passando-se a requerer capital também para outros tipos de derivativos.

Após a desvalorização de nossa moeda, no início de 1999, houve uma evolução do requerimento de Capital Regulamentar no Brasil - Resolução 2.606 -, pois com o colapso de instituições como o Banco Marka e o Banco Fonte-Cindam, percebeu-se a necessidade de requerer capital para exposições em metais preciosos (especificamente ouro), além daquelas atreladas a 
moedas fortes - como o dólar norte-americano e o iene.

Finalmente, um último componente importante referente a Capital Regulamentar no Brasil surge com o requerimento de capital para operações remuneradas a taxas pré-fixadas na moeda local, dada pela Resolução 2.692, que requer capital para o trading e o banking book. Um ponto negativo desta Resolução é que ela não cobre exposições ao risco de mercado de taxas de juros em outras moedas, ações e commodities - o que não é desprezível em certos casos, considerando-se que algumas instituições brasileiras têm porções importantes de seus balanços expostas a esses riscos.

Apesar desses avanços, ainda não há requerimento de capital para riscos operacionais no mercado brasileiro. Haja vista que o NACB irá, até 2006, exigir capital para riscos operacionais nos países do G10, podemos esperar que este requerimento ocorra em um futuro próximo em nosso mercado.

Também diante da maior sofisticação sugerida pelo NACB para riscos de crédito, é razoável que a metodologia de cálculo de capital na Resolução 2.099 seja modificada para se adequar ao ambiente regulamentar que surgirá nos países do G10. O requerimento de capital de forma diferenciada, dependendo do risco de crédito embutido em cada operação (por exemplo: rating e prazo), deve ser o principal aprimoramento nesse caso. Um passo importante nessa direção já foi dado pela Resolução 2.682 (Banco Central do Brasil, 1999), quando padronizou as escalas de ratings entre os bancos no país. O histórico obtido pela Central de Riscos de Crédito (Banco Central do Brasil, 2000) pode ser usado para construir matrizes de migração para diferentes segmentos do mercado, permitindo o mapeamento das escalas de ratings locais para as escalas internacionais - como Moody's ou Standard \& Poor's e, por fim, a elaboração de uma versão local para o standardized approach descrito no NACB para os países do G10.

Porém, é necessário incluir outros derivativos no cálculo do capital para riscos de crédito desses instrumentos financeiros. Um maior nível de transparência nessas posições deve ser requerido de forma a minimizar possíveis colapsos financeiros, ou pelo menos evitar perdas volumosas nos casos em que não houve colapso (Steinherr, 2000). A utilização da metodologia de cálculo de margens divulgada pela Bolsa de Mercadoria e Futuros é um caminho a ser seguido no caso de se incluir a demanda de capital para posições em contratos futuros e opções. Em relação ao mercado a termo, a metodologia para swaps pode ser eficientemente adap- tada, pois o processo de mapeamento de riscos nos dois casos é bastante parecido.

O desenvolvimento de metodologias para estimação do value-at-risk (Jorion, 1997) de posições sujeitas ao risco de mercado evoluiu substancialmente na rotina das instituições brasileiras nos últimos anos, apesar de algumas dificuldades, como quando se está sob condições atípicas de mercado, como no caso dascrises mexicana, asiática e russa (Duarte, 1997). A verdade é que, embora sempre surjam críticas ao valueat-risk, essa é uma medida de riscos de mercado que faz parte da rotina das instituições locais e internacionais, tendo se transformado na principal medida hoje usada por praticantes e regulamentadores.

A supervisão bancária deve garantir que as instituições financeiras usem prudentemente o value-at-risk em suas rotinas. Não se pode esquecer que, para condições atípicas de mercado, a utilização de cenários de estresse é fortemente recomendada como complemento ao value-at-risk, como ilustrado com exemplos reais por Duarte (1997). Já é possível unificar o requerimento de capital para riscos de mercado, cobrindo riscos de taxas de câmbio, taxas de juros, ações e commodities, em uma só estimação, usando-se o value-at-risk para tal. Uma nova resolução com esse fim pode substituir as resoluções existentes, cobrindo fontes de riscos de mercado ignoradas até aqui.

Um último ponto a ser mencionado em relação ao processo de requerimento de Capital Regulamentar para bancos brasileiros diz respeito ao modo como o Banco Central do Brasil deveria agir diante de casos em que houvesse insuficiência de capital. Uma possibilidade interessante é dada pelo novo sistema de ratings para bancos que esteve em desenvolvimento até recentemente, e que deverá estar em uso em breve no trabalho da supervisão direta do Banco Central do Brasil. Nesse caso, os bancos brasileiros passarão a receber ratings da supervisão bancária, que não serão tornados públicos, mas servirão de base para a atuação preventiva por parte desse órgão supervisor, em linha com o sugerido no segundo pilar do Novo Acordo de Capital da Basiléia. A proposta da metodologia Risk-Based Capital (National Association of Insurance Comissioners, 2001) para o mercado segurador norte-americano ilustra como os órgãos supervisores podem agir em casos em que há uma deterioração percebida nos níveis de Capital Regulamentar e pode ser usada de base para o desenvolvimento de uma metodologia similar para bancos no Brasil. 


\section{Alocação de capital regulamentar em seguradoras no Brasil}

O conceito utilizado pelo Conselho Nacional de Seguros Privados para demandar capital às seguradoras no Brasil é o de "margem de solvência". Esta pode ser definida como o mínimo excesso de ativos sobre passivos que é necessário para fazer frente a perdas devidas para eventos inesperados (European Parliament, 2002). Nessa questão em particular, o ambiente regulamentar brasileiro foi, até aqui, muito influenciado pelo ambiente regulamentar europeu e, em particular, pelo projeto Solvência I (European Parliament, 2000a, 2000b).

O projeto Solvência I foi refletido no Brasil na Resolução CNSP 55 (Conselho Nacional de Seguros Privados, 2001), que requereu das seguradoras (com exceção do ramo vida) uma margem de solvência que pode ser calculada de acordo com a seguinte fórmula:

máximo $\{20 \%$ dos prêmios de 1 ano; $33 \%$ da média anual de sinistros de 3 anos\}

No entanto, somente a utilização da Resolução CNSP 55 é insuficiente para cobrir os riscos de seguradoras no Brasil. O ambiente regulamentar para o mercado segurador local terá de evoluir bastante para que pelo menos o nível de sofisticação existente para bancos seja atingido, no que se refere ao estabelecimento de um requerimento mínimo de capital.

A argumentação de que bancos e seguradoras operam em atividades diferentes não é aceitável para explicar o ambiente regulamentar deficiente para capital mínimo de seguradoras no Brasil (Cumming e Hirtle, 2001; International Actuarial Association, 2002; Saita, 1999). A Comissão das Comunidades Européias já discute hoje o projeto Solvência II, que propõe lançar mão de abordagens mais sofisticadas para o cálculo de capital mínimo. O projeto sugere examinar aqueles elementos ainda não considerados pelo cálculo atual, como os arranjos de resseguros, o nível de provisões técnicas, a política de investimentos - considerando riscos de mercado e crédito -, o gerenciamento conjunto de ativos e passivos, e riscos operacionais. Trata-se de um conjunto de regras que irá utilizar modelos mais sofisticados de quantificação de riscos e cujo principal objetivo caminha em paralelo ao do Novo Acordo de Capital da Basiléia. Tais regras irão determinar de forma mais precisa a constituição de um capital mínimo em função dos riscos assumidos (European Parliament, 2001a, 2001b).
Em linha com essa tendência, os relatórios da International Association of Insurance Supervisors estabeleceram que o capital de uma seguradora deve ser capaz de absorver perdas inesperadas decorrentes dos vários tipos de riscos relacionados à sua operação. $\mathrm{O}$ valor desse capital deve refletir o tamanho, a complexidade e os riscos assumidos pela empresa, devendo ser função do nível de riscos presentes (International Association of Insurance Supervisors, 2000, 2002).

Além disso, o relatório Bank for International Settlements (2001b) traz uma padronização para a identificação de riscos em companhias seguradoras, segregando-os em três grandes grupos: o primeiro é composto pelos riscos técnicos, tais como de apreçamento de produtos (novos ou antigos) e o nível de provisionamento técnico; o segundo é formado pelos riscos de investimentos, principalmente os de crédito e mercado; e o terceiro é composto pelos riscos nãotécnicos, principalmente os operacionais e legais.

Vemos aqui uma insuficiência da cobertura da Resolução CNSP 55, no que se refere à exigência de capital para que as seguradoras consigam enfrentar os riscos inerentes a seus negócios: essa resolução não faz sequer menção ao requerimento de capital para riscos de investimentos e não-técnicos.

Existe no cenário internacional um modelo regulamentar de requerimento de capital que satisfaz em grande parte os requisitos listados nos três parágrafos anteriores: trata-se da metodologia Risk-Based Capital (RBC), desenvolvida nos Estados Unidos e posteriormente adaptada e adotada por países como Canadá e Japão.

Há três fórmulas para o cálculo do RBC, cada uma aplicada a um ramo segurador: vida, saúde e ramos elementares. Essa distinção deve-se ao fato de que os riscos assumidos pelas companhias diferem em grau e característica nesses três ramos de atuação (Atchinson, 1996). O Quadro 2 traz um sumário da identificação dos principais riscos presentes em seguradoras segundo o RBC, e suas definições e relações com os riscos em bancos, quando existentes.

O Quadro 2 serve também de base sobre como proceder para adequar o ambiente regulamentar das seguradoras ao ambiente regulamentar dos bancos: vemos que os riscos de ativos, de crédito, de taxas de juros e do negócio descritos nesse quadro estão todos relacionados aos riscos de mercado, crédito e operacionais presentes na rotina de bancos. Como o risco de crédito embutido em uma debênture no ativo de uma seguradora em nada difere do risco de crédito 
dessa mesma debênture no ativo de um banco, nada mais razoável do que exigir capital em ambos os casos. De forma similar, os riscos de mercado oriundos de títulos públicos federais no ativo de uma seguradora em nada diferem daqueles presentes nas mesmas posições das tesourarias de bancos, devendo resultar, portanto, na mesma demanda de capital.

$\mathrm{Na}$ questão de capital para riscos de crédito em seguradoras há itens que não possuem correspondência em bancos: o risco de existência de prêmios ou sinistros não recuperáveis, gerados por contratos de resseguros ou cosseguros, e os repasses de prêmios - garantia estendida, estipulantes etc.

Para o caso particular de resseguros, as seguradoras no mercado brasileiro operam em grande medida com o Instituto de Resseguros do Brasil (IRB), possuindo, entretanto, resseguros contratados com grupos internacionais. E, para o caso de cosseguros cedidos e aceitos entre seguradoras no mercado brasileiro, estes geram um montante de prêmios e sinistros que irá compor boa parte dos ativos de seus balanços. Nesse sentido, o risco de inadimplência por parte de resseguradoras e cosseguradoras deve ser considerado no cálculo de requerimento de capital. Como a Resolução 2.682 exige que todas as contrapartes de bancos tenham ratings, e como os bancos operam com seguradoras, os ratings das seguradoras já devem estar pron- tos. Para as resseguradoras, a utilização de ratings gerados por agências classificadoras de crédito é uma primeira alternativa (por exemplo, a Standard \& Poor's já produziu um rating para o IRB), depois de serem convertidos para a escala interna da instituição. Observamos, portanto, que as exposições de crédito devido a resseguros e cosseguros podem ser facilmente cobertas pelas metodologias desenvolvidas para as demais exposições de crédito dos bancos, sem perdas em termos de precisão. O mesmo vale para o caso de repasses de prêmios.

No entanto, existem questões específicas que demandam tratamentos diferenciados. Por exemplo, os riscos operacionais de fraudes em seguradoras diferem dos riscos operacionais de fraudes nas operações de cartões de crédito e débito em bancos. Embora a metodologia de cálculo para a exigência de capital nesses casos deva ser específica para cada caso, o conceito geral de exigir capital para fazer frente a riscos operacionais de fraudes é o mesmo em ambos os casos. Aqui, as metodologias propostas pelo NACB podem ser usadas de base para o ambiente regulamentar das seguradoras.

Finalmente, existem os casos específicos da natureza das seguradoras, como o risco de seguros descrito no Quadro 3. Nesses casos, a metodologia deve ser desenvolvida pelas próprias seguradoras, já que esse é o

Quadro 2 - Principais riscos presentes em seguradoras: ramos elementares e vida e saúde.

\begin{tabular}{|c|c|c|c|}
\hline \multicolumn{2}{|c|}{ RAMOS ELEMENTARES } & \multicolumn{2}{|l|}{ VIDA E SAÚDE } \\
\hline $\begin{array}{l}\text { RISCO EM } \\
\text { SEGURADORAS }\end{array}$ & $\begin{array}{l}\text { RISCO EQUIVALENTE } \\
\text { EM BANCOS }\end{array}$ & $\begin{array}{c}\text { RISCO EM } \\
\text { SEGURADORAS }\end{array}$ & $\begin{array}{l}\text { RISCO EQUIVALENTE } \\
\text { EM BANCOS }\end{array}$ \\
\hline $\begin{array}{l}\text { Risco de ativos: perdas por declínio no va- } \\
\text { lor de mercado de ativos por fatores de } \\
\text { mercado - como taxas de juros - ou degra- } \\
\text { dação creditícia - incluindo inadimplência }\end{array}$ & Mercado e crédito & $\begin{array}{l}\text { Risco de ativos: perdas por declínio no va- } \\
\text { lor de mercado de ativos por fatores de mer- } \\
\text { cado - como taxas de juros - ou degrada- } \\
\text { ção creditícia - incluindo inadimplência }\end{array}$ & $\begin{array}{l}\text { Riscos de mercado } \\
\text { e crédito }\end{array}$ \\
\hline $\begin{array}{l}\text { Risco de crédito: perdas devido a resse- } \\
\text { guros e cosseguros }\end{array}$ & Não há & $\begin{array}{l}\text { Risco de seguros: perdas devido a um } \\
\text { apreçamento errado de produtos e servi- } \\
\text { ços - novos ou antigos -, ou de um com- } \\
\text { portamento adverso dos sinistros }\end{array}$ & Não há \\
\hline $\begin{array}{l}\text { Risco de apreçamento de seguros: per- } \\
\text { das pelo apreçamento inadequado de } \\
\text { produtos e serviços, ou constituição ina- } \\
\text { dequada de reservas }\end{array}$ & Não há & $\begin{array}{l}\text { Risco de taxas de juros: perdas decorren- } \\
\text { tes de variações nas taxas de juros, redu- } \\
\text { zindo o valor de mercado dos ativos ou } \\
\text { aumentando o custo de refinanciamento } \\
\text { da instituição financeira }\end{array}$ & Risco de mercado \\
\hline Risco extra-balanço & $\begin{array}{l}\text { Risco de mercado } \\
\text { e crédito }\end{array}$ & $\begin{array}{l}\text { Risco do negócio: perdas decorrentes de } \\
\text { diferentes atividades operacionais da } \\
\text { empresa }\end{array}$ & Riscos operacionais \\
\hline
\end{tabular}


ramo de conhecimento específico das mesmas. O capital demandado das seguradoras no Brasil pela Resolução CNSP 55 serve para cobrir basicamente esse tipo de risco.

A metodologia RBC identifica riscos e aplica fatores sobre determinados montantes, produzindo uma estimativa para o capital a ser alocado para fazer frentes a riscos. Ao final, a seguradora obtém o capital mínimo requerido para todo o grupo, permitindo que as autoridades supervisoras façam uma comparação ao capital existente para a seguradora. Nesse ponto, duas definições importantes surgem: primeiro, o nível de Controle Autorizado (NCA), que representa o requerimento mínimo de capital calculado para uma determinada seguradora segundo o RBC; e segundo, o Capital Total Ajustado (CTA), que representa o capital real da seguradora, obtido após alguns ajustes contábeis.

O Quadro 3 resume as ações que devem ser tomadas pela autoridade supervisora, dependendo da relação entre o Nível de Controle Autorizado e o Capital Total Ajustado. É um conjunto similar de ações como essas que a supervisão bancária poderia considerar implementar no Brasil, dando maior transparência à sua forma de atuação, como sugerido no segundo e no terceiro pilar do Novo Acordo de Capital da Basiléia.

Os modelos de requerimento de capital para seguradoras no Brasil ainda são função do comportamento de sinistros, prêmios e provisões técnicas. A metodologia $\mathrm{RBC}$ representa um substancial avanço em direção à adoção de técnicas mais sofisticadas que visam a captar de forma mais precisa os riscos assumidos pelas companhias. O ambiente regulamentar brasileiro para seguradoras terá de avançar nessa direção, como está fazendo a Comunidade Européia por meio do projeto Solvência II, aproximando-se do requerimento de capital para bancos.

De forma similar, a autoridade regulamentar britânica, em seu relatório técnico Financial Services Authority (2001), defende a existência de um ambiente regulamentar unificado para bancos e seguradoras, sob o argumento de que o capital deve ser função dos riscos assumidos, independentemente do mercado em que a instituição opera.

\section{PROPOSTA DE UNIFICAÇÃO DO AMBIENTE REGULAMENTAR}

Há quatro pontos no ambiente regulamentar de requerimento de capital para bancos no Brasil que poderiam evoluir diante da nova regulamentação internacional que está surgindo, fundamentalmente impulsionada pelo NACB: primeiro, o estabelecimento do requerimento de capital para riscos operacionais, hoje inexistente; segundo, a evolução da metodologia de requerimento de capital para riscos de crédito em direção a métodos de quantificação que busquem identificar de forma mais precisa o risco presente nos ativos; terceiro, a inclusão de demais derivativos no cálculo de capital para riscos de crédito desses instrumentos - hoje, somente swaps são considerados; e, por fim, a unificação da demanda para riscos de mercado, cobrindo juros, câmbio, ações e commodities, no cálculo de requerimento de capital.

No caso específico das seguradoras, o ambiente regulamentar de requerimento de capital no Brasil é insuficiente para cobrir todos os riscos presentes em suas

Quadro 3 - Ações da autoridade supervisora para seguradoras.

\begin{tabular}{|l|l|}
\hline \multicolumn{1}{|c|}{ SITUAÇÃo } & \multicolumn{1}{c}{ AÇÃo } \\
\hline $1,5 \mathrm{NCA} \leq \mathrm{CTA}<2,0 \mathrm{NCA}$ & $\begin{array}{l}\text { Supervisão requer apenas o envio de um plano de ação contendo propostas para ação } \\
\text { corretiva, visando subir a razão entre o CTA e o NCA }\end{array}$ \\
\hline $1,0 \mathrm{NCA} \leq \mathrm{CTA}<1,5 \mathrm{NCA}$ & $\begin{array}{l}\text { Além das ações acima, a Supervisão poderá realizar um exame geral das operações da } \\
\text { seguradora e, se julgar necessário, requerer algumas ações corretivas }\end{array}$ \\
\hline $0,7 \mathrm{NCA} \leq \mathrm{CTA}<1,0 \mathrm{NCA}$ & $\begin{array}{l}\text { Supervisão poderá realizar um exame geral das operações da seguradora e, se julgar } \\
\text { necessário, poderá intervir no grupo segurador }\end{array}$ \\
\hline $\mathrm{CTA}<0,7 \mathrm{NCA}$ & $\begin{array}{l}\text { Supervisão é obrigada por lei a intervir no grupo segurador. Há a possibilidade de este } \\
\text { passo ser apenas adiado por } 90 \text { dias, caso se julgue provável que o CTA do grupo se } \\
\text { mova para a faixa do nível acima }\end{array}$ \\
\hline
\end{tabular}

Nota: CTA e NCA designam, respectivamente, Capital Total Autorizado e Nível de Capital Autorizado. 
atividades. Nossa proposta para o mercado segurador baseia-se fundamentalmente no argumento de que o capital deve ser função dos riscos assumidos, independentemente do mercado em que a instituição opera. Pensamos que o ambiente regulamentar brasileiro deve ser unificado na questão específica de requerimento de capital para bancos e seguradoras.

A forma de identificação das fontes de riscos, seu mapeamento e quantificação, devem ser independente do mercado de atuação de uma instituição. Por exemplo, não pode haver distinção entre os riscos de mercado e crédito, presentes em uma mesma debênture, no ativo de uma seguradora ou de um banco. Naturalmente, riscos específicos presentes em seguradoras, e não em bancos, devem ter tratamento singular, em linha com o proposto na metodologia RBC.

Acreditamos que, dessa forma, o ambiente regulamentar brasileiro, no que diz respeito à questão específica de requerimento de capital, evoluiria em direção à adoção das melhores práticas internacionais de gestão de riscos em conglomerados financeiros, gerando maior solidez, segurança e benefícios significativos para o funcionamento do mercado em que essas instituições operam.

\section{DIFICULDADES À IMPLANTAÇÃO DA PROPOSTA}

O primeiro passo para uma efetiva alocação de capital é garantir entendimento e comprometimento com os conceitos até aqui colocados. Ainda não fazem parte do conhecimento da maioria dos membros da alta administração de bancos e seguradoras, conceitos como capital econômico, probabilidade de inadimplência, gestão de riscos operacionais etc. Na ausência de um comprometimento da alta direção dessas instituições com o processo de alocação de capital, e de um claro entendimento de toda a organização sobre seus benefícios, o processo ficará comprometido (Matten, 1998).

No caso particular das seguradoras, há ainda a necessidade de um processo educacional em relação à gestão de riscos. A quase totalidade das seguradoras brasileiras ainda não provisiona suas perdas esperadas devido a riscos de crédito ou riscos de mercado. Há a necessidade de ocorrer algum tipo de provisionamento para perdas de crédito - a Resolução 2.682 seria um bom passo nessa direção - antes que a necessidade de alocar capital para fazer frente a riscos de crédito seja plenamente entendida. A geração uma cultura de gerenciamento de riscos com uma visão corporativa ainda terá de passar por um estágio preliminar no caso de seguradoras, enquanto que no caso de bancos essa cultura já está mais disseminada. Nossa expectativa é de que a questão da cultura de gerenciamento de riscos represente uma dificuldade prática a ser vencida no desenvolvimento de um ambiente regulamentar mais sofisticado para requerimento de capitais em seguradoras no Brasil.

Uma outra dificuldade prática que os agentes locais de regulamentação deverão analisar é a adaptação e calibragem das propostas internacionais para o ambiente brasileiro. As propostas existentes nos mercados internacionais foram desenvolvidas para normas contábeis e regras operacionais diferentes das nossas, e que devem ser entendidas pelas autoridades de regulamentação brasileiras, sendo seus impactos cuidadosamente testados. Adicionalmente, questões totalmente inovadoras para o mercado brasileiro, como, por exemplo, o requerimento de capital para o risco de seguros (ver Quadro 2), trariam dificuldades iniciais para sua implementação devido a uma série de fatores que podem variar desde o preciso entendimento dos conceitos requeridos até a existência de uma base de dados adequada, passando ainda pela qualificação e supervisão da metodologia de cálculo utilizada.

\section{CONCLUSÕES}

Alocar capital em bancos e seguradoras ainda é um assunto pouco entendido pelos executivos locais, além de virtualmente ausente dos principais encontros acadêmicos brasileiros. Esse é, no entanto, um dos mais importantes trabalhos que uma área para gestão de riscos corporativos pode realizar em um banco ou seguradora, pois ajuda a garantir a solvência, além de indicar à alta direção quais são as atividades geradoras de valor e quais as atividades destruidoras de valor.

Uma alocação de capital bem realizada traz maior segurança e transparência às atividades da instituição financeira. Para tal fim, há a necessidade de um trabalho analítico inicial detalhado, especialmente na identificação de riscos - em unidades de negócio, produtos, serviços e processos de tomada de decisão -, para que se obtenham resultados de utilidade prática para a instituição.

Para o caso particular de bancos, vimos que não são tantas as fragilidades que devem ser consideradas pelas autoridades de regulamentação. Um ponto impor- 
tante é a existência de um conjunto de procedimentos objetivos, de conhecimento dos participantes do mercado no que se refere à forma de atuação da supervisão bancária quando houver deterioração no montante de capital disponível para fazer frente a riscos. Uma possibilidade é adaptar as regras hoje existentes para as seguradoras norte-americanas à realidade dos bancos no Brasil. Não nos esqueçamos, entretanto, que a elaboração de uma metodologia para conferir ratings às instituições financeiras no Brasil já é um passo importante nessa direção, em linha com o recomendado no segundo pilar do NACB.

Há hoje uma clara discrepância entre as tendências das abordagens de requerimento de capital regulamentar em bancos e seguradoras no Brasil: entre os bancos há uma tendência em acompanhar as melhores propostas do ambiente regulamentar internacional; o mesmo não pode ser dito no caso das seguradoras.

Neste ensaio, propusemos a unificação do ambiente regulamentar brasileiro na questão específica de requerimento de capital para bancos e seguradoras. Essa proposta está baseada na comparação e customização dos ambientes de regulamentação internacional e local, além da incorporação das melhores práticas internacionais de gestão de riscos. Reconhecemos que existem dificuldades práticas que devem ser consideradas para a implementação de nossa proposta. Por exemplo, preparar os gestores de seguradoras no Brasil para que se desenvolva uma cultura corporativa de gestão de riscos. Outros pontos importantes são a adequação de ajustes contábeis à realidade do Brasil, além da adaptação de metodologias para as características do mercado local.

Acreditamos que, se implementada, essa proposta gerará um ambiente regulamentar mais saudável e transparente, com uma melhor alocação de capital, facilitando o trabalho das autoridades supervisoras e provendo mais segurança aos clientes de bancos e seguradoras.

Por fim, é importante mencionar que existem vários temas que demandarão pesquisa acadêmica no que se refere ao problema da alocação de capital em bancos e seguradoras. Um desses temas é a questão do estabelecimento de uma metodologia que permita a variação da demanda de capital ao longo de ciclos econômicos. Não há, hoje, nenhuma regulamentação - local ou internacional - que incorpore essa questão. Este é, certamente, um tema de pesquisa em aberto que demandará trabalho conjunto de executivos, agentes de regulamentação e acadêmicos.

\section{REFERÊNCIAS BIBLIOGRÁFICAS}

ATCHINSON, B. K. The NAIC's risk-based capital system. NAIC Quarterly, v. 4, n. 2, p. 1-9, 1996

BANCO CENTRAL DO BRASIL. Resolução 2.099. Brasília: Banco Central do Brasil, 1994.

BANCO CENTRAL DO BRASIL. Resolução 2.682. Brasília: Banco Central do Brasil, 1999.

BANCO CENTRAL DO BRASIL. Resolução 2.724. Brasília: Banco Central do Brasil, 2000.

BANK FOR INTERNATIONAL SETTLEMENTS. International convergence of capital measurement and capital standards. Basel: Basel Committee on Banking Supervision, 1988.

BANK FOR INTERNATIONAL SETTLEMENTS. The new Basel capital accord: consultative document. Basel: Basel Committee on Banking Supervision, 200la.

BANK FOR INTERNATIONAL SETTLEMENTS. Risk management practices and regulatory capital: cross sectoral comparison. Basel: Basel Committee on Banking Supervision, 2001b.

CONSELHO NACIONAL DE SEGUROS PRIVADOS. Resolução 08. Rio de Janeiro: Superintendência de Seguros Privados, 1989.

CONSELHO NACIONAL DE SEGUROS PRIVADOS. Resolução 55. Rio de Janeiro: Superintendência de Seguros Privados, 2001.

CROSS, M.; HERSHBARGER, R. Use of risk-based capital to analyze reinsurer solvency. In: FIFTH INTERNATIONAL CONFERENCE ON INSURANCE SOLVENCY AND FINANCE, 1997, Roma. Anais... 1997.

CUMMING, C. M.; HIRTLE, B. J. The challenges of risk management in diversified financial companies. New York: Federal Reserve Bank, 2001. (Technical report).

DUARTE JR., A. M. Model risk and risk management. Derivatives Quarterly, v. 3, n. 2, p. 60-72, 1997.

DUARTE JR., A. M.; PINHEIRO, F. A. P.; JORDÃO, M. R.; BASTOS, N. T. Gerenciamento de riscos corporativos: classificação, definições e exemplos. Resenha BMEF, n. 134, p. 25-32, 1999.

DUARTE JR., A. M.; JORDÃO, M. R.; GALHARDO, L. C.; KANNEBLEY, R. F.; SCAION, D.; SCHIDLOW, M.; CONÍLIO, M. A. M. Controles internos e gestão de riscos operacionais em instituições financeiras brasileiras: classificação, definições e exemplos. Resenha BMEF, n. 143, p. 40-4, 2001.

EUROPEAN PARLIAMENT. Directive 2000 /12 /CE on the solvency margin requirements for life assurance undertakings. Bruxelas: European Parliament, 2000a.

EUROPEAN PARLIAMENT. Directive 2000/13 /CE on the solvency margin requirements for non-life assurance undertakings. Bruxelas: European Parliament, 2000b.

EUROPEAN PARLIAMENT. Note to the solvency subcommittee. Subject: riskbased capital systems. Bruxelas: European Parliament, 2001a. (Technical report). 
EUROPEAN PARLIAMENT.'Note to the solvency subcommittee. Banking rules: relevance for the insurance sector? Bruxelas: European Parliament, 2001b. (Technical report)

EUROPEAN PARLIAMENT. Study into the methodologies to assess the overall financial position of an insurance undertaking from the perspective of prudential supervision. Bruxelas: European Parliament, 2002. (Technical report).

FEDERAL RESERVE SYSTEM. Assessing capital adequacy in relation to risk at large banking organizations and others with complex risk profiles. Washington: Division of Banking Supervision and Regulation, 1999. (Technical report).

FINANCIAL SERVICES AUTHORITY. Integrated prudential sourcebook. London: Financial Services Authority, 2001. (Technical report)

FROOT, K. A.; STEIN, J. C. Risk management, capital budgeting and capital structure policy for financial institutions: an integrated approach. Journal of Financial Economics, v. 47, n. 1, p. 55-82, 1998.

HALLERBACH, W. G. Capital allocation, portfolio enhancement and performance measurement:'a unified approach. Roterdam: Erasmus University, 2001. (Technical report).

HOOKER, N. D.; BULMER, J. R.; COOPER, S. M.; GREEN, P. A. G.; HINTON, P. H. Risk-based capital in general insurance. British Actuarial Journal, v. 2, n. 3, p. 265-323, 1996.

INTERNATIONAL ACTUARIAL ASSOCIATION. A commentary on the consultative document Principles on capital adequacy and solvency. Ottawa: International Actuarial Association, 2002. (Technical report).

INTERNATIONAL ASSOCIATION OF INSURANCE SUPERVISORS. Insurance core principles methodology. Basel: International Association of Insurance Supervisors, 2000. (Technical report).

INTERNATIONAL ASSOCIATION OF INSURANCE SUPERVISORS. Principles on capital adequacy and solvency. Basel: International Association of Insurance Supervisors, 2002. (Technical report).
JORION, P. Value at risk. New York: MacGraw Hill, 1997.

LÉLIS, R. J. F; DUARTE JR., A. M. Alocação de capital em bancos no Brasil. Tecnologia de Crédito Serasa, n. 31, p. 6-28, 2002.

LOFRANO, C. E. S. Gerenciamento de carteiras de créditos dos bancos: uma visão regulatória. Tecnologia de Crédito Serasa, n. 24, p. 8-15, 2001.

MATTEN, C. Managing bank capital: capital allocation and performance measurement. New York: John Wiley \& Sons, 1998.

NATIONAL ASSOCIATION OF INSURANCE COMMISSIONERS. Riskbased capital kit. Kansas City: National Association of Insurance Commissioners, 2001.

PAYANT, W. R. Ways of assigning capital to lines of business. Bank Accounting E Finance, v. 2, n. 1, p. 33-8, 1996.

SAITA, F. Allocation of risk capital in financial institutions. Financial Management, v. 14, n. 2, p. 77-89, 1999.

SHEPHEARD-WALWYN, T.; LITTERMAN, R. Building a coherent risk measurement and capital optimization model for financial firms. New York: Federal Reserve Bank, 1998. (Technical report)

SOARES, R. P. Evolução do crédito de 1994 a 1999: uma explicação. Rio de Janeiro: Instituto de Pesquisas Econômicas Aplicadas, 2001. (Relatório técnico).

STEINHERR, A. Derivatives, the wild beast of finance: a path to effective globalization? New York: John Wiley \& Sons, 2000.

STOUGHTON, N. M.; ZECHNER, J. Optimal capital allocation using $R_{A R O C^{T M}}$ and EVA®. Irvine: University of California, 1999. (Technical report).

STOUGHTON, N. M.; ZECHNER, J. The dynamics of capital allocation. Irvine: University of California, 2000. (Technical report).

THOMSON, J. B. Economic capital and the new Basel capital accord. Cleveland: Federal Reserve Bank, 2001. (Technical report).

Artigo recebido em 03.02.2003. Aprovado em 08.09.2003.

\section{Antonio Marcos Duarte Júnior}

Professor e Coordenador do Mestrado em Economia e da área de Finanças \& Controladoria da Faculdades Ibmec /RJ. Doutor em Matemática Aplicada pela Princeton University, EUA. Interesses de pesquisa em mercado de capitais, finanças corporativas e métodos numéricos em finanças.

E-mail: aduarte@ibmecrj.br

Endereço: Av. Rio Branco, 108, 5oandar - Rio de Janeiro - RJ, 20040-001.

\section{Rogério José Furigo Lélis}

Analista Sênior de Riscos no Unibanco S. A. Pós-graduado em Finanças pela USP/Fipe. Interesses de pesquisa em risk management, regulação e supervisão do sistema financeiro.

E-mail: rogerio.lelis@unibanco.com.br

Endereço: Rua Indiana, 118, apto. 84, Brooklin - São Paulo - SP, 04562-000. 